\title{
La fuerza motriz, en la obra dramática de Rodolfo Usigli
}

No parece casualidad que Rodolfo Usigli publicara su primera comedia en 1932, con el título de El apóstol. Más bien, el autor se reveló como el apóstol del teatro mexicano, vocación que sigue desde hace veinte años. Se ha dicho de él que el teatro es su religión. Contribuyó Usigli a la creación del teatro mexicano, como autor dramático, director, traductor, profesor de arte dramático y también autor de obras de crítica y análisis literario. Lo que trata de superar es la crisis en el teatro mexicano, aunque la considera como un fenómeno inseparable del Teatro, como lo es del Comercio o de la Bolsa. Según Rodolfo Usigli, no hay crisis teatral donde no hay obras. ${ }^{1} \mathrm{Al}$ reunirse autor, intérpretes y público, el éxito viene sin faltar. En su lealtad hacia al realidad mexicana; en su intención de dar expresión a México, la obra de Usigli alcanza una proyección universal. La honradez profesional del autor, contribuye al desarrollo de la técnica y de la conciencia de la renovación del teatro mexicano.

En su investigación de los estilos en el teatro, Rodolfo Usigli hace una distinción clara entre el realismo y la realidad: ésta siempre se está transformando, mientras que aquél no viene a constiuirse en un estilo claro y personal sino a fines del siglo xix. Además, Usigli reconoce un realismo moderno en el cual pugna la realidad psicológica con la realidad corriente, y otro realismo, mágico, en el cual el hombre trata de establecer una realidad nueva. En el teatro poético la poesía es un encuentro con la realidad que permanece intacta. 
Rodolfo Usigli, el apóstol de un nuevo estilo en el teatro mexicano, aconseja "una celosa observación de los estilos de obras dramáticas." En el teatro idealista, asi como en las comedias realistas clásicas, no cabe la tesis; no encierran una moral definida, a la inversa de las comedias románticas del siglo xIx. El teatro idealista es más bien el fin que el medio de llegar al fin. La acción se representa como algo que está en el proceso de desarrollo, dominado por la emoción que está en las manos del dramaturgo. Sólo al intentar distinguir entre los estilos, México podrá contribuir a la formación de un nuevo estilo en el teatro. "Hay que empezar a hablar del problema hoy mejor que mañana." 2 No cabe duda de que el teatro en México no tiene una vida perfecta porque México no ha entrado aún en la plenitud. Usigli procura mejorar y reformar, con su crítica. Fiel a sí mismo, resulta iconoclasta blasfemo; sobre todo, por envilecer las maneras de la sociedad elegante mexicana.

En su obra dramática hay dos tendencias claramente determinadas: una trata de las costumbres sociales en México, y a pesar de su intenso color local, of rece una crítica severa de la situación universal, que une su tema con la humanidad. A esta clase de obras pertenecen: La mujer no hace milagros (1939), La familia cena en casa (1942), Medio tono (1938), El gesticulador (1943), y La iiltima puerta (1948).

El otro grupo más bien se ocupa en la psicología del hombre moderno, con los problemas que atormentan el alma humana, hasta convertirse en estados de introspección psicopáticos o conducir al borde de la locura, que se revela de varias maneras. A ese grupo pertenecen: El niño y la niebla (1936-1949), Otra primavera (1945), Sueño de día (1940), La función de despedida (1949) y Jano es una muchacha (1952).

Corona de sombras (1943-1947), no puede quedar limitada en ninguno de estos grupos, aunque es una pieza basada en la historia política, y motivos psicopáticos resultan de la situación.

La mujer no hace milagros, La familia cena en casa y Medio tono, del primer grupo, forman una trilogía ideológica. Lo que tienen en común no es el asunto, sino que muestran y detallan la evolución y la decadencia de la familia mexicana. Exponen tres tipos diferentes, y se completan entre sí. La mujer no hace milagros expone el gran mundo del México elegante, en su pleno y decadente apogeo. 
En La familia cena en casa este tipo ya ha llegado a menos, y en Medio tono la familia de la clase media se va desmoronando.

La mujer no hace milagros ${ }^{3}$ es una pieza de costumbres y de convenciones sociales, parecidas a las de La familia cena en casa. Las equivocaciones se aclaran al fin, y los escándalos acaban por no serlo de veras. Victoria, la hija mayor de la familia Rosas, está descontenta porque a su esposo le importan demasiado las tareas caseras. Casi se deja llevar a una aventura por Roberto, amigo de su hermana menor. Sin embargo, no pasa la noche con él, como lo sospechaba su familia, sino con su prima Elsa, y al vover a casa y saber que su esposo Alejandro está por salir de viaje a Sudamérica, nada impide la reconciliación entre los dos. Roberto Dávila es un escéptico ingenuo que declara repetidas veces que "la mujer no hace milagros". No se da cuenta de que Herminia está enamorada de él. Para ganar su simpatía y realizar "el milagro", Herminia finge una intriga amorosa, con un amigo mutuo y conquista el corazón de Roberto.

De lema a La familia cena en casa ${ }^{4}$ le sirve la siguiente frase del autor: "El arte del teatro consiste en recordar con la ayuda de la imaginación". Este también es un drama de convenciones sociales, o más bien, de costumbres. Demuestra lo absurdo de los prejuicios y de la murmuración. La complejidad consiste en los enredos de la sociedad y las equivocaciones. Los Torres Mendoza son muy ricos, y la viuda of rece a sus hijos todas las ventajas de la alta sociedad, así como las de la libertad, con el resultado de que Gilda, la hija mayor, lleva una vida en la que se mezcla con bohemios. Estela se ha divorciado por no tener hijos, y Julieta, la menor, va posponiendo su casamiento con Felipe porque ambas familias son demasiado ricas. E1 hijo, Carlos, lleva una vida frívola, y una noche, ya borracho, lo insulta Enrique Ramírez diciéndole que su padre ha robado una fortuna a los Ramírez. Para distraer la atención de la sociedad, de la deshonra de su difunto padre, Carlos se casa con la cabaretera Beatriz. Piensa frenar la calumnia del nombre de su padre causando un escándalo nuevo. La señora Torres Mendoza prepara una cena para 500 personas, $y$ en esta ocasión presenta a su nuera Beatriz, aunque sea una "cualquiera". Después de haber impedido al joven Ramírez que causara un escándalo en la fiesta, la señora explica a él y a sus hijos que el padre de los Ramírez acumuló mu- 
chas deudas. Para evitar el pago, legó su propiedad a su amigo Torres Mendoza. Este, por ser buen negociante, multiplicó la fortuna y durante varios años ayudó à la viuda Ramírez con grandes cantidades. Sin embargo, la vieja fué a Monte Carlo y lo perdió todo. Ahora la familia se mantiene sólo por la misericordia de la viuda Torres Mendoza. Al oír esta explicación, Enrique se va, avergonzado de su imprudencia anterior. ¿Y Beatriz? Esperaba quedarse para salvar a la familia del escándalo. Pero se descubre que Beatriz no es tina "cualquiera". Ella también es de buena familia que la echó por una "culpa" suya. Sin embargo, ya que no hay escándalo y no hay necesidad de advertirlo, Beatriz se decide a dejar a Carlos y a seguir a Fernando, que la ama de veras, sin hacer caso de su linaje.

En Medio tono, ${ }^{5}$ comedia de costumbres de la clase media en desmoronamiento, escrita en cuatro días, la familia también está preparando la cena, como en la comedia anterior. Es domingo y desfilan todos los hijos de la familia Sierra. Gabriela tiene dos novios; Victor sólo se interesa en sus trajes y su elegancia; Julio es comunista ; Martín, aficionado a los perros, es "l'enfant terrible" de la familia, y David, tísico y siempre cuidado por todos los demás. El carácter del petimetre Víctor se parece mucho al de Ricardo de $L a$ mijer no hace milagros, y también al cínico hijo menor Alberto de Otra primavera.

La familia Sierra se halla en un estado de desintegración moral y económica. Sin embargo, para superar la crisis, se reúnen en el supremo esfuerzo de salvar su triste destino. Guardan el decoro invirtiendo el último centavo en el camino separado de cada hijo.

Martín vende su perrito para conseguir cincuenta pesos. El señor Sierra ha sacrificado todos sus bienes, para librar de la cárcel a Julio. Van en distintas direcciones siguiendo cada uno sus propias ideas. A pesar de las luchas interiores de caracteres, demuestra la familia el instinto de rebaño, de resignación y de sacrificio que unen a los miembros de la familia en los momentos de peligro. En esta obra Rodolfo. Usigli se ocupa de conflictos de la vida, de los dilemas que someten a prueba el alma y el espíritu humanos.

De la disidencia del principio resulta la concordia de la familia, a medida que se empeoran las circunstancias de su vida. Los Sierra son una clase media universal, de un pueblo que atraviesa las fronteras del nacionalismo. Al estrenarse en 1937, la obra suscitó una 
polémica entre los izquierdistas y los derechistas: ambos pretendían enarbolarla en defensa de sus ideas políticas. Nada de eso estaba en la intención del autor. Veamos qué tendencias siguió en sus otras obras.

En El gesticulador ${ }^{6}$ también hay un padre fracasado en la vida práctica y por eso le falta autoridad dentro de su familia, como al señor Sierra. Las familias de las tres comedias están en una decadencia evidente. La analogía es también clara en el caso de las hijas, no sólo en el de los padres. Gilda y Gabriela tienen corazones esquizofrénicos: ni siquiera saben decidirse por uno de sus novios. Los hijos de Sierra van por diferentes caminos: Sara va a tener un hijo ilegítimo; Julio va a la guerra a España, para salir del "medio tono" de la clase media de México; Martín sigue en su falta de disciplina y de respeto, y Victor en su amor del lujo. A pesar de eso, los padres están tunidos en la idea de no "matar los deseos de sus hijos." Por ellos se mundan de casa, por ellos sacrifican sus bienes. Y la única preocupación del padre es: "Creo que hemos hecho bien; pero no sé si habremos hecho lo bastante." Sus problemas son humanos pero forman un conjunto artificial que otorga una vista caleidoscópica del género. La coherencia de la familia tiene algo conmovedor y sentimental; mas para producir efecto persuasivo, son demasiados problemas. La pieza es más bien una hazaña de realización técnica que una obra de gran fuerza dramática.

En el epílogo a El gesticulador trata el autor de la hipocresía mexicana. Otra vez encontramos a un padre que fracasó en la vida práctica. Como profesor de historia, nunca ganó lo bastante para mantener a su familia. Sin embargo, el decoro fué guardado rigurosamente hasta que los Rubio se decidieron a mudarse al pueblo natal del profesor. Allí surgió un "Deus ex machina" en la persona del profesor norteamericano Oliver Bolton, en busca de datos sobre la vida de un general de la revolución, César Rubio. ¿Es una casualidad que nuestro héroe, tocayo y coetáneo de aquél, haya nacido en el mismo pueblo? Alentado por el momento propicio, el historiador César Rubio se convierte en el general César Rubio. Tiene documentos importantes de la revolución y de su tocayo, y vendiéndolos al profesor norteamericano, consigue dinero y la fama de ser el ilustre general. A su mujer, Elena, ya acostumbrada a la pobreza y a las privaciones, le explica César: "Todo el mundo aquí vive de apariencias, 
de gestos. Yo he dicho que soy el otro César Rubio. ¿A quién perjudica eso? ... Yo soy mejor... que muchos de los que viven de la mentira..." 7

Aunque los personajes de esta sátira politica parecen más bien titeres que hombres de carne y hueso, reaparecen tipos ya conocidos de otras piezas del autor, como la Gilda de La familia cena en casa, quien parece carecer de corazón; como la Gabriela de Medio tono, quien vacila entre dos novios; como la Herminia de La mujer no hace milagros, quien deja al público adivinar su emoción hasta la escena final del último acto, así también Julia, la hija de César Rubio, al abandonar a su novio, explica: "Lo que amaba en él era la fuerza, la decisión, el poder; el dinero, la influencia - todo lo que no tenía en mi alrededor ni en mí. Pero ahora lo tengo, y él no importa. Tendré que buscar en otro hombre otras cosas que no tenga." $s$

Desde el momento en que se apropia la identidad del general, el profesor Rubio cambia de actitud. ¿ Por qué no pudo probar su talento en la vida anterior? Falta alli una transición, una explicación de este cambio repentino del fracaso continuo al éxito y el poder. La misma falta de desarrollo se nota en el carácter de Miguel, hijo de jos Rubio. El único rasgo sobresaliente de su carácter es la debilidad y falta de respeto, lo que ya notamos en el adolescente Martín, en Medio tono. A pesar de no hacer más que papeles secundarios, las mujeres de El gesticulador representan caracteres más sinceros y más vivos que los hombres; sobre todo Elena, cuya devoción absoluta y su lealtad al amor, persiste sin hacer caso del poder, de la gloria, de las riquezas. Parecería que el destino de la familia Rubio ha cambiado. Pero en el momento culminante, el profesor-general muere a manos de asesinos del bandido - general Navarro, quien se hace elegir gobernador, en vez de su rival- víctima, i en nombre del progreso y de los ideales de César Rubio! La ironía del destino pierde a la familia Rubio, después de tantas vicisitudes. La pieza debe también demostrar que la gesticulación es típicamente mexicana. Dice el autor, en el epílogo: "César Rubio gesticula, pero Navarro, un tipo más común en nuestra historia, compite en gesticular con él, porque no puede afrontar la verdad, porque profesa, como todo mexicano, la idea de que la verdad lo perdería..."9 $\mathrm{He}$ aquí una de las declaraciones críticas sobre la nacionalidad del autor, de las que el público no quiere oír ni ver representadas en la escena, y a causa 
de las cuales Usigli siempre es una fuerza perturbadora en el teatro mexicano. Usigli presenta la crítica sin indicar la solución del problema, mientras el público prefiere que lo diviertan. Por eso sufre el "apóstol" Usigli hasta llegar a ser mártir de la verdad; a no ser entendido ni aplaudido por el término medio de su público, cuando trata asuntos políticos, cuando critica las costumbres mexicanas contemporáneas; sin embargo, al observar esos problemas de cerca, tenemos que confesar que se trata de costumbres y de vicios más bien universales que puramente mexicanos. Esto puede decirse igualmente de las debilidades del sistema político y social y de los caracteres retratados en El gesticulador y en La iltima puerta. ${ }^{10} \mathrm{~A}$ primera vista, se diría que La illtima puerta es una sátira exclusivamente mexicana. Se burla de la pereza burocrática, y es una colección de chistes y juegos de palabras. En la sala de espera la gente aguarda al ministro que nunca aparece. Se demuestra la ineficacia del gobierno y 10 absurdo de las peticiones. Mientras esperan, pasa mucho tiempo. Aunque le falta acción, la sátira contiene lo cómico y lo crítico juntos. Según el autor, corresponde la pieza a la realidad mexicana, que es una realidad "inmoral y política". Sin embargo, al lector le impresiona como una invención puramente irreal y teatral lo que se resume en la pregunta del periodista: “¿Existe o no el señor ministro?" y en su propia contestación: "todo ha terminado; el señor ministro ha demostrado que existía, en el momento mismo en que dejó de existir..." En esta declaración final se refiere no sólo a las esperas interminables del sistema burocrático universal, sino también a los cambios políticos frecuentes en muchas partes del mundo. Después de tanta espera, el ministro sin aparecer, manda su despedida a los pretendientes porque "acaba de presentar su dimisión."

Presentar una tesis de cómo, cuando y por qué el dramaturgo desarrolló su interés por las profundidades del alma humana, sería presuntuoso y vano. Baste decir que lo demostró con una comprensión extraordinaria y que vuelve a los motivos subconcientes y a los estados al borde de la razón y la locura, con evidente predilección. El niño y la niebla ${ }^{11}$ fué concebido como un experimento, con fines de estudio y de disciplina. A pesar del fin tan sobrio, no le falta emoción interna ni movimiento interior e íntimo de positiva humanidad, no dominado por las circunstancias o por la época. Primero 
fué escrito el tercer acto; diez días más tarde, el primero, y finalmente el segundo. La catarsis del tercer acto podría muy bien servir de exposición: aclara que Marta Estrada es de una familia de locos. "Me he pasado la vida ... huyendo... de mí misma... Toda mi familia es de locos...", confiesa a su amante Mauricio. Marta odia. a su esposo Guillermo, por ser el padre de Daniel y odia a éste por la locura hereditaria que teme en él o en sus hermanos no nacidos. Por su aprehensión ha destruído las ambiciones de Guillermo y se niega a volver a la capital, para no encontrarse con su madre o hermana locas. Por una casualidad, en el primer acto sabe que Daniel es sonámbulo. Causa la crisis e inculca en el sueño de su hijo, el odio hacia su padre con el resultado de que la noche crítica el niño dormido se acerca a Guillermo, con una pistola en la mano; pero en vez de matarle, se suicida.

Muerto el hijo, los esposos se quedan en el pueblo juntos: Marta, por expiación; Guillermo, por tratar de saber la causa del suicidio de Daniel. La anécdota central fué relatada al autor por una norteamericana, en 1934. En la realidad, la madre logró que el niño matara a su padre, y el jurado la condenó como culpable. Compartió con Usigli el interés en la herencia psicopática, su amigo Xavier Villaurrutia. Discutieron el caso y ambos volvieron al mismo astunto varias veces, desde el año en que estudiaron juntos en la Escuela de Teatro de la Universidad de Yale.

Aunque Otra primavera ${ }^{12}$ fué escrita desde 1938, fué estrenada hasta 1945 y se publicó hasta 1947. También fué estrenada por un grupo experimental de Nueva York, en 1951. En esta pieza reaparece el motivo antes mencionado, con un magnetismo especial, como vamos a ver, al examinar el asunto:

¿Por qué volvió la familia de la hacienda, en noviembre, cuan1do todos los años anteriores permanecía fuera de México hasta la Navidad? Lo ignoran Arturo, el padre, y Amelia la madre. Raúl, el hijo mayor, encargado de los negocios de la familia, tuvo que vender la hacienda y lo hizo sin que lo supieran los demás, porque sospecha la locura hereditaria de su padre. ¿O su sospecha se debe a su deseo de obtener el control de los bienes de la familia para sí, deshaciéndose del papá? Así interpretan su idea el hermano menor, Alberto, y su hermana Marta, al principio; pero después de la con- 
sulta con Xavier, médico y amigo de la familia, se convencen todos de que la locura de Alberto es incurable.

Berta, la mujer de Raúl, teme dar a luz a un niño que pueda heredar la locura; pero Amelia le da ánimo para dejar seguir la marcha de la vida. Al principio, Amelia ${ }^{13}$ se niega a creer que la locura de esposo sea incurable: "No creo en la locura como en un estado anormal de las gentes; más bien como en algo que habita con ellas, en su casa, que llena la mitad de su cuerpo . . L La locura es energía. Sólo es enfermedad cuando no tiene objeto. Tu padre, Raúl ha siempre tenido un objeto en su vida..." El bisabuelo construyó una casa en forma de tumba, sin ventanas, el abuelo era un perseguidor perseguido; el padre de Arturo se volvió loco, y Arturo tiene la locura de querer "abrir las ventanas". El grande amor conyugal ya iba perdiéndose, pero la decisión de Amelia les dará ocasión a los esposos de vivir "otra primavera". Dicen a Arturo que Amelia está enferma incurablemente y los dos van a quedarse en su casa, juntos, sólo con dos criados, Amelia fingiendo la locura y Arturo pensando que tiene que cuidarla y curarla sin separación y sin manicomio.

El tema central es la repetición del tema de El niño y la niebla: la locura hereditaria, el miedo a ella, y las consecuencias que de esta situación resultan. Berta no quiere a su hijo futuro, como Marta odiaba a Daniel, por miedo de la herencia de la familia desequilibrada. En ambos casos se complica la situación por la igonrancia de uno de los esposos, de los antecedentes hereditarios. (Guillermo Estrada ignoraba lo de la familia de Marta, como Berta ignoraba lo de la familia de Raúl.) Falta, "clara pacta", la base sana del matrimonio. El interés acentuado en la psicopatía no ocurre sólo por casualidad. Repetido con insistencia extraordinaria, es un interés elemental. Aunque le falta acción y suspensión al segundo acto, hay en Otra primavera una sencillez y una profunda comprensión del alma humana, la cual culmina en la compasión y en el sacrificio de Amelia en el tercer acto. A la inversa de las piezas mordaces de ambiente político, aquí no hay más que emoción humana, sin atacar a nadie. Hasta el sacrificio de Amelia es más bien un caso de conciencia que un problema dramático. Es interesante notar que en 1950 fué llevada al cine con la cantante argentina Libertad Lamarque y Ernesto Alonso, agregándole canciones. 
Al concebir Sueño de dia ${ }^{14}$ se propuso el autor hacer una pieza de teatro que pudiera "representarse a la vista del público sin eliminar al elemento mismo que la generó ... y que es la radio..." La idea de la pieza le fué sugerida por la lectura del último artículo que escribió el neurólogo Alfredo Adler.

Su parentesco con las piezas mencionadas anteriormente consiste en la importancia de los sueños. Daniel, el niño, vive en la niebla; actúa dormido, llevando a cabo los proyectos delineados por su madre. En Otra primavera, Arturo, loco por herencia, se cree sano mientras Amelia finge la enfermedad para seguir viviendo con él la "otra primavera" de su amor.

La realidad y la ficción creada en sueños o en el pensamiento, se compenetran hilvanando el tejido de motivo común a todo este grupo de piezas dramáticas.

En Sueño de día se trata de tna soñadora diurna que con su complejo de inferioridad ha construido un castillo en el aire. No sólo cree en la realidad de las cosas soñadas, sino también en la persona imaginada e imaginatia. Clementina es una mujer de 29 años, a quien descuida su esposo Xavier aunque está enamorado de ella, porque él espera el mejoramiento de su posición antes de tener hijos. Entretanto Clementina se enamora del fantasma radiofónico que le canta tangos bajo el nombre de "Caballero": Tan fuerte llega a ser su pasión, que se siente en cinta y se prepara a dejar a su esposo para irse con el "Caballero" y dar a luz a su hijo. Xavier, enterado del asunto, cree que el niño esperado no es suyo, e incitado por su hermana Rousaura mata a su mujer. Cuando, después, quiere matarse, Rosaura se lo impide. Demasiado tarde vuelve Luis, amigo de la familia, para explicar la situación: enviado por Clementina, fué al estudio radiofónico, sólo para descubrir que el "Caballero", a quien buscaba con el recado de Clementina, era la voz del difunto Carlos Gardel, grabada en discos. La infidelidad de Clementina no era más que un "sueño de día". La policía prende al asesino Xavier ... : la realidad sucede fatalmente a los sueños.

La función de despedida ${ }^{15}$ también es una mezcla de sueños y de realidad. Fué escrita para Virginia Fábregas "que ya no pudo representarla..." E1 destino de los comediantes está presentado con los sueños falsos y con las realizaciones, en la vida y en la escena. La protagonista, primera dama de las tablas, ha dedicado toda la vida 
al teatro; hasta sacrificó el amor y la vida de familia, para realizar su sueño. Después de tantos años vuelve a su pueblo, y desilusionada por el fracaso de su compañía trata de suicidarse. Dos veces la vuelve a la vida el doctor porque "la señora ha estado actuando sin interupción durante todos estos días..." Los sueños creados en la imaginación de la actriz tenían más fuerza que los barbitúricos y que la estricnina; el deseo de hacer teatro venció a la desilusión del fracaso. Fingiendo o pensando que va a morir, dice Verónica: ... "ya no hay teatro ... E1 teatro se acabó ... Yo me acabé ..." iQue se acabe A teatro con ella! Pero la realidad es distinta: A pesar de los éxitos del cine, a pesar de las dificultades que hay que superar, el teatro no se acabó, y con él va a seguir la actriz: "Soy actriz; tragedia o comedia, es lo mismo, con tal de actuar... Yo tenía que morir ... pero también tenía que salir a recibir los aplausos ... o los silbidos ... A mi nadie me roba la frase del telón." . . . concluye Verónica devuelta a la vida y a la carrera de actriz. También va a realizar el sueño de la joven Marina Cruz y ayudarle a hacerse actriz. Este sueño nació en Marina a causa de una lectura, en la biblioteca de su padre, que coleccionaba todas las obras estrenadas por Verónica. En la juventud ya lejana, fué novio de la actriz nacida en su pueblo. Más tarde Verónica salió del puebló siguiendo el llamado del teatro y fué rechazada por su familia.

El amor de Manuel por ella, se quedó en sueño sin cumplir. Ahora sólo se realiza en la reaparición de Verónica y en la carrera teatral de Marina, alentada por aquélla.

En esta pieza la actitud psicopática que es el centro del interés, es mucho más moderada que en las piezas anteriores del mismo grupo. En El niño y la niebla y en Otra primavera se trataba de locura hereditaria y del temor a ella. Sueño de día creó consecuencias reales, basadas en una ficción. En la Función de despedida los sueños se realizan por la fuerza creadora de la imaginación, y también por la fuerza inmortal que es el teatro. Lo psicopático se limita a inocente histeria. Fundamentalmente la pieza es una apología del teatro, y su afirmación, a pesar de los movimientos contrarios y hostiles; a pesar de los éxitos del cine; a pesar de la poca comprensión del público y de los críticos; a pesar del egoísmo de los actores y de la falta de autores dramáticos. El teatro no morirá, como ya no 
morirá la actriz Verónica. Dentro de los problemas psicológicos, se reconoce aquí el artículo más firme de la fe usigliana.

Hasta ahora, la pieza más original de Rodolfo Usigli, en concepto y forma, es Jano es una muchacha. ${ }^{16}$ Contiene todo lo requerido para "épater le bourgeois" y, sin embargo, logró un éxito extraordinario. Dos escenas de los primeros dos actos pasan en el burdel, lo que, sin duda, bastaría para la exclusión completa de algunos escenarios. Además, se trata del problema del sexo, lo que aumentó el escándalo causado por el éxito de Jano. Pero ningún punto de vista moral o inmoral pudo cambiar lo dramático de la pieza, lo que atrae al público y mantiene su interés como lo hizo Jano. La mayor parte de los críticos se opuso a la pieza, sosteniendo que es indecente y que está mal construída y es falsa; muchos la rechazaron por el carácter melodramático de los elementos que se precipitan desde el final del segundo acto hasta el final del tercero; el consenso general de la crítica fué adverso al tercer acto.

Víctor, el hombre amoral que padece de inhibiciones sexuales, fué juzgado y condenado como destructor de tres vidas: la de su mujer difunta, Arcelia; la de su asesina Eulalia; la de su hija, Marina, sin contar la suya propia. Eulalia, su cuñada, es conocida por su temple: hace muchos años mató su yegua predilecta, de un tiro. Ya está preparada para destruir de un balazo en la frente a Víctor, único hombre a quien ha querido. Marina, la muchacha Jano, con dos caras, es una ecuación no resuelta. El público que llegó con la esperanza de ver escenas inmorales, salió desilusionado, pero no desinteresado: la fuerza dramática de la pieza mantuvo a todos en los asientos, sin pestañear. ¿Que es falsa la pieza? ¿Que no es verdad que muchos mexicanos - o más bien, muchos hombres-, según sus recursos económicos, llevan una vida sexual doble, en su casa y fuera de ella? Además cuenta el autor ${ }^{17}$ un caso de la vida real que le sirvió de inspiración para el asunto de Jano: conocía a una pareja, casada honradamente y con un hijo. La mujer era una ex prostituta, Y él había robado dinero a su familia, antes de irse con la mujer que prefería. El fracaso moral y social que había de esperar se convirtió en éxito, y las dos vidas se unieron en moral y felicidad.

Siendo bastante raro el asunto de Jano, puede explicarse la objeción de un crítico ${ }^{18}$ a quien le hacía el efecto de la música moderna, que hay que oír varias veces, para apreciarla. Uno de los es- 
pectadores dijo: 19 "Jano es inmoral sólo para los inmorales", y esto está comprobado en el argumento: El padre -destructor de vidasdueño del burdel, es castigado por un tiro mortal. Su hija Marina, no sucumbe al peligro al que la expuso la inclinación sexual morbosa de sus padres. En lugar de eso, va a casarse con Felipe, un hombre decente, amigo de la familia. Sólo Eulalia, la solterona que lleva a cabo la justicia, se queda abandonada, como lo ha estado en toda su vida anterior. El sexo es la causa del sufrimiento, de todos los movimientos y acciones de los personajes de Jano. Además, hay la vida doble de Marina-Mariana: las dos caras de la -muchacha - Jano.

Es más que el sexo, lo que la mueve. Es una curiosidad juvenil, es un atavismo, es la busca del pasado y del futuro desconocido, es el complejo de fuerzas latentes en su alma, el secreto del subconsciente parecido a los sueños que dirigieron los actos de los protagonistas de las cuatro piezas mencionadas anteriormente.

Las dos categorías principales abordadas por Rodolfo Usigli son el problema político-social y el problema sexual, con interés en el lado psicopático y en lo subconciente y con la combinación melodramática de la realidad y los frutos de la imaginación.

Corona de sombras ${ }^{20}$ no puede clasificarse en ninguna de esas categorías. Sin embargo, abarca la esfera de los dos: Es una imagen retrospectiva de lo que sufrió Carlota por el fracaso y la muerte de Maximiliano, y al mismo tiempo es la presentación de la debilidad y de las vicisitudes nacionales mexicanas. Según el autor, "el héroe de Corona de sombras es México, ... y sólo cuando Carlota divaga... adquiere su vida escénica honda resonancia personal..." 21

En eso el autor insiste, afirmando en otra parte: "Mi intención no es otra que expresar a México".

Para ofrecer un análisis completo de la obra de Rodolfo Usigli tendríamos también que mencionar la colección de poemas publicada en 1938, en Cuadernos Americanos, bajo el título de Conversación desesperada o la novela Ensayo de un crimen, del año 1944, además de varias piezas inéditas. Desdichadamente en este punto tenemos que volver a citar al autor mismo, cuando dice: ${ }^{22}$ "El teatro en México se imprime lo menos posible y por eso está generalmente mal escrito... Donde toda obra es impresa (v. g. en Francia), las malas desaparecen con los años... las buenas tienen todas las facilidades de perdurar ..." 
iOjalá llegara el teatro mexicano a tal punto de su evolución! Así podríamos conocer las obras escritas, estrenadas o no. Mientras tanto, tenemos que limitar nuestro interés a las pocas obras impresas. Por mucho que nos limitemos, llegamos a la misma conclusión: en el teatro de Rodolfo Usigli sólo hay lugar para lo que está vivo. Como la política ejerce gran influencia en la vida nacional de México, también importa en el teatro legítimo, y como los motivos psicopáticos, el desmoronamiento de las familias y la conexión entre la vida y los sueños son una realidad viva, aunque a menudo incongrua, forma todo eso una parte integral e imprescindible de la obra dramática de Rodolfo Usigli, en su continua batalla por el teatro mexicano.

VERA F. DE BECK.

\section{$\mathrm{NOTAS}$}

1 "Las tres dimensiones del teatro", capítulo del libro en preparación: "La llamada al teatro", Asomante, vr, núm. 2, 1950. Suplemento de Novedades, 1949-1950.

2 Itinerario del autor dramático. La Casa de España en México, 1940.

3 Comedia en tres actos. Suplemento de América. Revista antológica. México, 1949.

4 En tres actos. En El Hijo Pródigo, año Ir, vol. vir. Enero-febrero, 1945.

5 Comedia en tres actos. Editorial Dialéctica. México, 1938. Estrenada por la Compañía de María Teresa Montoya, en 1937.

6 Pieza para demagogos, en tres actos, escrita en 1938, estrenada en 1947. El Hijo Pródigo, I, núms. 2-4, mayo-julio, 1943.

7 Acto II, p. 175. Ediciones de El Hijo Pródigo, 1944.

8 Acto III, p. 249, ibid.

9 Cantar de gestos, p. 204, ibid.

10 Farsa en dos escenas y un ballet intermedio, escrita en 1934-1936. (Publicada en la revista Hoy, en marzo, 1948.)

11 Escrita en 1936 y reajustada en 1949; pieza en tres actos publicada por la Unión Nacional de Autores en 1951.

12 Pieza en tres actos. Sociedad General de Autores. México, 1950. 
13 Acto II.

14 Radiodrama en un acto. Revista de América, núm. 59, 1949. Estrenado por el teatro radiofónico, en 1939.

15 Comedia de la vida de los comediantes, en tres actos, escrita en 1949, estrenada en 1952. Publ. en el Suplemento México en la Cultura, 1951.

16 Pieza en tres actos. México, 1952. Estrenada en el Teatro Colón de la ciudad de México, 1952, como quinta obra de la temporada auspiciada por la Unión Nacional de Autores, bajo la dirección de Luis Basurto Jr.

17 Prólogo a Jano es una muchacha, p. 43.

18 Addenda después del estreno, p. 179.

19 Ibid., p. 179.

20 Pieza antihistórica en tres actos y once escenas, publ. en Cuadernos Americanos, II, 6, 1943; estrenada en 1947.

21 "Las tres dimensiones del teatro". Capítulo del libro en preparación: "La llamada al teatro". Asomante, vi, 2, 1950, pp. 55-60. Suplemento de Novedades, 1949-1950.

22 Prólogo a la Bibliografía del teatro en México, de Francisco Monterde, 1933, p. 78 . 
